\title{
The relationship between type of secondary education and subject choice with technically oriented aptitudes for automotive operators
}

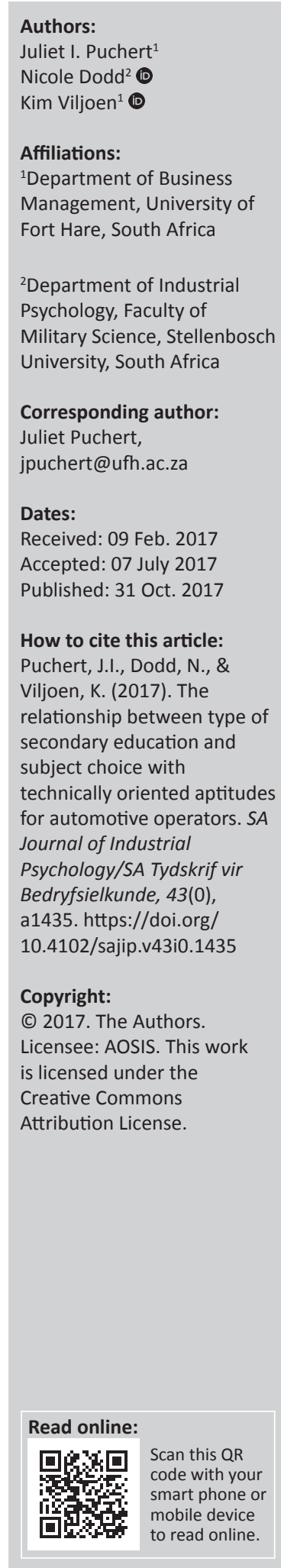

Orientation: The central theme of this study attends to the role of secondary education in relation to two broad categories of specific aptitudes (psychomotor and spatial abilities). Utilising type of secondary education (incorporating subject choice) could be a crucial selection mechanism for high-volume, entry-level technical positions.

Research purpose: The objective of this research was to investigate whether the type of secondary education (incorporating subject choice) could be used as a proxy for psychomotor (dexterity and coordination) and/or spatial (ability to mentally assemble representations and spatial perception 2-D and 3-D) aptitudes in the selection of operators for an automotive plant in South Africa.

Motivation for the study: The motivation for this study arose from the evident gap in academic literature as well as the selection needs of the automotive industry.

Research design, approach and method: A quantitative approach with a cross-sectional research design was used with a convenience sample $(n=1566)$ of work-seeking applicants for automotive operator positions in South Africa. These applicants completed a biographical questionnaire and five sub-tests from the Trade Aptitude Test Battery. The Chi-square test was used to determine the association between form of Grade 12 qualification and selected technical aptitudes.

Main findings: Statistically and practically significant relationships were found between type of secondary education (incorporating subject choice), eye-hand coordination and spatial visualisation. Broad performance levels in the five aptitude instruments employed in this study were significantly associated with the type of matriculation certificate held by applicants. Specifically, types of secondary education that included mathematics and/or science as subjects were associated with higher levels of performance in the five specific aptitudes.

Practical/managerial implications: The type of secondary education (incorporating subject choice) held by applicants could be regarded as a key predictor variable in human resource selection. The study makes a case for a multiple-hurdles approach to selection and proposes a cost-effective preliminary screening method for low-level technical positions.

Contribution/value-add: The study provides information to improve upon selection practices within the South African automotive industry. It could also assist human resource practitioners in designing selection processes for similar entry-level employees in other working contexts. The study makes a case for a multiple-hurdles approach to selection and highlights the reciprocal relationship between education and specific cognitive abilities in the science, technology, engineering and mathematics fields.

\section{Introduction}

In their pursuit of optimising the human capital in organisations, South African (SA) human resource management practitioners are facing the challenges of a volatile, complex and ambiguous environment. Increased digitisation, amplified technological change, an increased focus on knowledge creation and globalisation means that a new set of competencies is required from employees (Ajith, 2015; Bennett \& Lemoine, 2014; Ramdass, 2009). Furthermore, SA employers, in particular in the automotive industry, increasingly need employees with sound technical knowledge and skills. Artisans and technicians are earmarked as people with scarce and critical skills in the SA manufacturing industry (Brown, 2013; Nzimande \& Patel, 2012; Peo, 2013). A scarce skill is one that has inadequate supply and a critical skill is regarded as being core to the 
sector (merSETA, 2009). This has meant that innovative selection methods need to be utilised to ensure there is a match with job requirements and that high-potential talent is identified (Piro, 2011; Shatouri, Omar \& Igusa, 2012; Van Hampton, 2007).

Gardner's (1983) multiple intelligences theory proposed that individuals are different from one another in their capacities and intellectual abilities. This philosophy of intelligence highlights the existence of a repertoire of human cognitive abilities. In Gardner's extension of his original model in 1999, he proposed that there are nine types of adaptive abilities or intelligences: logical and mathematical, verbal and linguistic, musical, visual and spatial, bodily and kinaesthetic, interpersonal, intrapersonal, naturalistic, and existential (Gardner, 1999).

The relationship between these multiple intelligences measured by tools of various abilities, representing psychological concepts, as well as the impact of differing teaching strategies on academic achievement have been broadly investigated. Varying degrees of correlation between these constructs have been found (Carretta \& Ree, 2000; Douglas, Burton \& Reese-Durham, 2008; Ekinci, 2014; Rohde \& Thompson, 2007). Significant ties between aspects of Gardner's multiple intelligence model and scientific achievement have been established. Specifically, several substantial longitudinal research studies have consistently shown that specific cognitive abilities, such as spatial and psychomotor aptitudes, play a significant role in academic achievements and innovations related to the STEM (science, technology, engineering and mathematical) areas (Johnson \& Bouchard, 2005; Kell \& Lubinski, 2013; Wai, Lubinski \& Benbow, 2009).

An important question regarding human capital therefore pertains to the relationship between education, training and cognitive skill formation (Brinch \& Galloway, 2011; Carlsson, Dahl, Öckert \& Rooth, 2015; Hunt, 2014). Research has indicated that scores on cognitive tests and schooling are positively associated (Carlsson et al., 2015). There is, however, also appreciation that there could be a reverse influence and that it is difficult to separate cognitive test scores from various compounding factors (Rohde \& Thompson, 2007).

Education could be an efficient resource in the selection of potential employees for STEM-related positions.

\section{Research purpose and objectives}

Advancement through the STEM fields underpins national wealth and is critical to the international competitiveness of countries. It serves as the foundation for research and development, innovation and the generation of a pool of sustainable entrepreneurs and business leaders (Harlan, 2014; Rindermann \& Thompson, 2011; Tucker Drob, Cheung \& Briley, 2014). Maximising STEM advancements should therefore be a critical target of educational policy (Hall, Dickerson, Batts, Kauffman \& Bosse, 2011; Rindermann \& Thompson, 2011; Tucker Drob et al., 2014).
However, international and national educational systems are not adequately preparing youth with the skills required to advance within the STEM fields. SA participates in three main cross-national assessments of educational achievement. In comparison to all the other participating middle-income countries, SA has the worst education system. In fact, SA performs worse than many low-income African countries in these educational achievement assessments (Spaull, 2013). Several gaps and misalignments in the SA educational system have been highlighted. Amongst these it has been identified that there is a mismatch of technical skills where the focus, level and quality of the training is inadequate (Mayer et al., 2011). Specifically, the SA Further Education and Training (FET) system has come under severe criticism over the past decade. Despite significant investments to enhance curriculum development and learner performance, the system has not achieved the anticipated output targets. This has exacerbated the increasing skills gap present in the SA potential labour market (Mayer et al., 2011; Ramdass, 2009; Smith, 2011). Rather, current educational curricula tend to be significantly more focused on verbal than on spatial abilities, resulting in a loss of students skilled in spatial ability or the reduction of achievement in this area by many individuals (Johnson \& Bouchard, 2005; Kell \& Lubinski, 2013).

Science, technology, engineering and mathematical-specific educational instruction has been found to influence students' interest and achievements in STEM fields. The implementation of various forms of hands-on STEM activities was found to raise or maintain positive STEM interests amongst students at a secondary school level (Christensen, Knezek \& TylerWood, 2015). A comprehensive review of the empirical research available to date revealed that spatial and psychomotor training offers a promising avenue for improving student performance in the STEM fields (Adanez \& Velasco, 2002; Hsi, Linn \& Bell, 1997; Kell \& Lubinski, 2013; Stieff \& Uttal, 2015; Wai et al., 2009).

The importance of spatial and psychomotor abilities in real work settings is evident in the literature. Studies have verified that level of aptitude and skill in these areas can be influenced by situational factors such as experience, education and training (Adanez, 2004; Adanez \& Velasco, 2002; Johnson \& Bouchard, 2005; Kell \& Lubinski, 2013; Kuncel \& Hezlett, 2010). Psychological tests assessing specific cognitive areas (i.e. spatial and psychomotor aptitudes) are more effective predictors of future performance than tests that measure broader areas, such as verbal and mathematical skills. Testing candidates' knowledge and skills within the particular course of study or career they are aiming to pursue is likely to result in the greatest return on investment as more ability in these areas results in enhanced performance (Kuncel \& Hezlett, 2010; Watkins, Lei \& Canivez, 2007).

The value of psychological aptitude tests therefore lies in their ability to successfully identify individuals with potential and those who are trainable in specific abilities (Foxcroft \& Roodt, 2013; Furnham, 2008; Ter Laak, Gokhale \& Desai, 2013). Cognitive and psychomotor tests have been found to 
be useful in employee selection for a wide variety of occupations, mostly being part of multiple-aptitude batteries (Carretta \& Ree, 2000). Research done by Hunter and Hunter (1984) revealed that psychomotor ability had greater incremental validity than general cognitive ability for less cognitively complex jobs, such as elementary industrial workers and vehicle operators. The import of assessing spatial ability was also highlighted in a longitudinal study, which revealed that spatial visualisation had a lower correlation with socio-economic status, in comparison to mathematical and verbal reasoning abilities (Shea, Lubinski \& Benbow, 2001). A compelling case for the logic in including spatial aptitude assessments in selection exercises for STEMrelated disciplines is put forward by Kell and Lubinski (2013). However, the vast majority of studies investigating psychological tests have pursued an investigation of the utility of using general cognitive ability tests to predict educational and vocational outcomes (Foxcroft \& Roodt, 2013; Furnham, 2008; Ter Laak et al., 2013). There is currently a lack of research on the impact of specific cognitive abilities, such as spatial and psychomotor aptitudes. Most of the research on spatial ability has been on its biological underpinnings. Therefore, there is a call for research to be done into the role of spatial and psychomotor ability on selection as well as the effect curriculum and training has on these aptitudes (Kell \& Lubinski, 2013; Shea et al., 2001). Very little research has been done on the secondary education factors that impact on spatial cognition and on the potential mechanisms that can be employed to improve these malleable skills (Stieff, Dixon, Ryu, Kumi \& Hegarty, 2013; Uttal et al., 2013a; Uttal, Miller \& Newcombe, 2013b).

It is with this in mind that this study sought to investigate the relationship between the technically oriented aptitudes and the forms of SA secondary education (incorporating subject choice). The secondary objectives of the study were stated as follows:

- To determine whether there is a relationship between level of eye-hand coordination and type of secondary education (incorporating subject choice) attained;

- To determine whether there is a relationship between the ability to mentally assemble representations and the type of secondary education (incorporating subject choice) attained; and

- To determine whether there is a relationship between candidates' spatial perception and the type of secondary education (incorporating subject choice) attained.

In order to address and expand on the abovementioned research objectives, the five primary research questions underpinning the project were:

- Is there a significant relationship between the type of secondary education (incorporating subject choice) obtained and hand-eye coordination ability?

- Is there a significant relationship between the type of secondary education (incorporating subject choice) obtained and one-hand-eye coordination?
- Is there a significant relationship between the type of secondary education (incorporating subject choice) obtained and the ability to mentally assemble representations?

- Is there a significant relationship between the type of secondary education (incorporating subject choice) obtained and 2-D spatial perception ability?

- Is there a significant relationship between the type of secondary education (incorporating subject choice) obtained and 3-D spatial perception ability?

In the section that follows, a literature review of the theoretical frameworks underpinning the study is provided alongside a review of the empirical literature in the research field.

\section{Literature review}

The structure and mechanisms of human intelligence have been researched for more than 100 years (Foxcroft \& Roodt, 2013; Furnham, 2008; Nisbett, 2013). A dominant model on the structure of human intelligence is the theory of fluid and crystallised (Gf-Gc) intelligence, initially developed by Cattell (1963) and developed further by Horn (1976). However, because of various criticisms, there has been a move away from this viewpoint of general intelligence (Ekinci, 2014; Johnson \& Bouchard, 2005; Nisbett, 2013; Shahzada, Khan, Ghazi \& Hayat, 2015).

Notably, a multiple perspective of intelligence was proposed by Vernon $(1964,1965,1969)$ and Humphreys (1962), who did not adhere to the commonly held belief of the time that the $g$-factor was a primary and important determinant of intelligence. Whilst Vernon (1969) upheld the importance of general intelligence, he did highlight that once the general intelligence factor was extracted from any compilation of ability tests, the residuals fell into two main categories. The first of these is labelled v:ed, referring to verbal and educational skills that assess verbal fluency, verbal and numerical scholastic knowledge as well as divergent thinking. The second residual is referred to as $k: m$ and unpacks spatial, practical and mechanical abilities, including perceptual speed and psychomotor abilities (Johnson \& Bouchard, 2005; Vernon, 1964, 1965, 1969). Empirical support and the practical importance of these two residual grouping of abilities were found in the prediction of work performance of sizeable military samples (Humphreys, 1962).

The focus of this study was on aspects of Vernon's (1969) k:m intelligence and two forms of Gardner's (1999) multiple intelligences, namely, bodily kinaesthetic intelligence (KI) and visual and spatial intelligence (SI). These specific cognitive abilities or aptitudes are narrower than general cognitive ability and tap into different hierarchical levels of human intelligence (Carretta \& Ree, 2000; Johnson \& Bouchard, 2005; Johnson, Nijenhuis \& Bouchard, 2007; Rohde \& Thompson, 2007). KI is an individual's capacity to skilfully utilise and control their body in terms of psychomotor activities. The effective employment of 
equipment and machinery are also expressions of this form of intelligence (Gardner, 1999). Also termed psychomotor ability, this form of intelligence measures skills such as finger dexterity, control precision, multi-limb coordination and rate control (Carretta \& Ree, 1997; Chaiken, Kyllonen \& Tirre, 2000). This study explored two types of psychomotor abilities: two-hand-eye coordination and one-hand-eye coordination in the first and second research questions. Spatial ability or SI is the capacity to visually perceive sensory data with the mind's eye and to accurately appreciate the technicalities of space. The ability to mentally rotate or manipulate this sensory input in space or given area is also included in this specific aptitude (Carroll, 1993). In this study, the third to fifth research questions investigate this form of specific aptitude through testing the applicants' ability to mentally assemble representations as well as their 2-D and 3-D spatial perception.

The different forms of intelligence appear to be differentially affected by environmental factors such as age, education and training (Carretta \& Ree, 2000; Watkins et al., 2007; Schmidt \& Hunter, 2004). International research has confirmed that spatial ability is an aptitude that can be improved with training (Adanez \& Velasco, 2002; Hsi et al., 1997). A large longitudinal study investigated the impact of mathematical, spatial and verbal assessments on a range of educationalvocational outcomes amongst high school students. An interesting corollary from this longitudinal study was that spatial ability has a lower correlation with socio-economic status (SES), relative to both mathematical and verbal reasoning abilities. More spatially intelligent individuals from lower SES levels could therefore be identified through the use of spatial ability measures (Humphreys, Lubinski \& Yao, 1993). Furthermore, a recent meta-analysis of 217 research studies established that spatial ability can reliably be improved through training. This meta-analysis investigated several moderators, including age, gender and type of training and found the findings to be stable across these moderators. Training effects were also confirmed to be durable and generalisable (Uttal et al., 2013a). This has also been supported at a tertiary level. Pre- versus postvisualisation test scores of first-year engineering students revealed that the teaching methodologies employed in developing this aptitude resulted in more than a third of the class increasing their performance on the test (Adanez, 2004). Training in spatial ability has been shown to be both durable and transferable. The impact of the training was observed months after the workshops and were being applied in tasks at least moderately different to those experienced in the training (Uttal et al., 2013b). Research conducted amongst first-year engineering students in Brazil highlighted that the early detection of students with low spatial aptitude, via a visualisation psychometric test, was able to improve these students' performance levels in technical drawing. The researchers also held that the elementary and high school activities in use at the time of the study did not adequately promote the development of spatial aptitudes within these Brazilian students (Adanez \& Velasco, 2002).
Currently, there is significant appreciation of spatial ability in general terms. However, there is still a gap in the literature pertaining to the attainment and development of SI in educational settings and the impact thereof on the occupational field (Johnson \& Bouchard, 2005; Kell \& Lubinski, 2013). In the range of multiple intelligences or the repertoire of human cognitive abilities present in human beings, SI needs to be explored further. This is especially necessary given the established link between this attribute and performance in the STEM fields (Kell \& Lubinski, 2013; Shea et al., 2001; Uttal et al., 2013a, 2013b).

Psychomotor and dexterity testing have also been increasingly used within the human resource management context (Foxcroft \& Roodt, 2013; Furnham, 2008). Psychomotor tests are readily employed as employee selection measures for apparel manufacturers. However, one study of sewing machine operators, in eight different plants, failed to show a significant relationship between the three psychomotor test scores and subsequent measured productivity (Inskeep, 1971). Psychomotor and dexterity testing have been successfully employed in the selection of students for surgical training (Gallagher, Leonard \& Traynor, 2009). Two spatial visualisation psychological tests, two-hand coordination and complex coordination tests were also used in the selection of pilots as part of a multiple-hurdles method (Bordelon \& Kantor, 1986). A manual dexterity test was furthermore employed to predict students' grades on courses at a pre-dental school to ascertain whether the students were ready to advance to the clinic. This test did not appear to add information to the current admissions criteria (Gansky et al., 2004).

The SA manufacturing sector requires high-level competencies in order to keep abreast of global competitiveness, the associated technological improvements and a significant increase in the prevalence of lean manufacturing practices (Mahembe, 2012; Nzimande \& Patel, 2012; Rauner, Heinemann, Hauschildt \& Piening, 2012; Shatouri et al., 2012). Well-developed practical and technical skills are therefore recognised as being vital in entry-level technician recruitment (Phillips, 2003). Empirical research conducted by the merSETA highlighted that $76 \%$ of the manufacturing sector's employers regarded these skills as fundamental in their recruitment of artisans (Peo, 2013).

The dilemma within the SA context is the selection hindrance created by the current inefficacy of the SA secondary education system (Deloitte, 2009). Education is the main cause of elevated skills and hence improved performance and productivity within a knowledge economy (Akinyemi \& Abiddin, 2013). However, a national survey investigating the main factors limiting the success of businesses in South Africa identified an insufficiently educated workforce as one of these determinants (Nzimande \& Patel, 2012). The achievement of a Grade 12 qualification should be a useful gauge for the measurement of skill levels in a country. However, it has been argued that the SA education system may be a deficient preparation base for employment and that the achievement of a secondary education may not be a 
dependable indication of learning capability (Cosser \& Sehlola, 2009; Lehohla, 2010; National Treasury, 2011).

The SA automobile industry has traditionally centred its recruitment and selection of entry-level employees on individuals with a technical education (Schafmeister, 2013). However, the number of learners who are graduating with technical Grade 12 qualifications that support entry and success at the higher educational level is not increasing proportionate to the increased demand for these skills (Mahembe, 2012; Nzimande \& Patel, 2012; Rauner et al., 2012). The merSETA has recently recommended a $50 \%$ or more pass in both mathematics and science for apprenticeship selection (Brown, 2013). In order to enhance the supply of adequately educated learners to the manufacturing sector, the merSETA has launched a number of projects that aim to improve Grade 12 mathematics and science performance (Patel, 2012; Peo, 2013). It is the intensified focus on the inclusion of these two subjects within the selection practices employed within the manufacturing sector that led to the study's five hypotheses:

- Hypothesis 1: There is a significant relationship between levels of dexterity and type of secondary education (incorporating subject choice) obtained.

- Hypothesis 2: There is a significant relationship between levels of coordination and type of secondary education (incorporating subject choice) obtained.

- Hypothesis 3: There is a significant relationship between assembly scores and type of secondary education (incorporating subject choice) obtained.

- Hypothesis 4: There is a significant relationship between spatial perception (2-D) and type of secondary education (incorporating subject choice) obtained.

- Hypothesis 5: There is a significant relationship between levels of spatial perception (3-D) and type of secondary education (incorporating subject choice) obtained.

For ease of reference, secondary education is understood as collectively referring to technical high schools, academic high schools and FET institutions. The terms 'secondary education', 'Grade 12 qualification' and 'matriculation' are hence used interchangeably. In this article, five forms of secondary education are named and defined as follows:

- A Grade 12 education with mathematics and science as subjects in a secondary education qualification obtained through an academic high school.

- A matriculation inclusive of mathematics as a subject in a secondary education qualification achieved at an academic high school.

- A Grade 12 qualification with science as a subject in a secondary education acquired at an academic high school.

- A technical-type matriculation, inclusive of mathematics and science as subjects, as attained through a technical high school or FET institution.

- A general type secondary education which does not include mathematics and science as Grade 12 subjects and is obtained at an academic high school.
The quantitative research design and methodology utilised is outlined in the section that follows, as well as the study's findings. Based on these findings, conclusions, recommendations and limitations of the research are provided.

\section{Research design Research approach}

A quantitative research methodology was followed to achieve the research objectives using a cross-sectional design. With a cross-sectional design, numerous individuals are examined at a specific point in time (Bryman, 2012; Neuman, 2012). This approach is appropriate for this study as it was economical and time effective. The study is descriptive in nature as the study aimed to investigate whether a relationship exists between secondary education (incorporating subject choice), eye-hand coordination and spatial abilities (Jankowicz, 2005). The sample that the research targeted was all the applicants who successfully completed the general aptitude phase in the selection process for operators within an automotive plant in the Eastern Cape. Mathematical literacy was not a subject investigated in this study. The type of sampling method used was convenience sampling, which involves selecting a sample according to the availability to the researcher (Quinlan, 2011). The data analysis was done by making use of the Chi-square test of independence to ascertain the relationship between the variables.

\section{Research method}

\section{Research participants}

This research formed part of a sizeable recruitment drive at a SA automobile plant. The target population was pre-screened according to two criterion employed by the organisation. Firstly, the candidates had obtained a Grade 12 qualification and had achieved a minimum stanine score of three on the general cognitive aptitude abilities (namely, verbal reasoning and non-verbal reasoning) previously assessed. As a result of these selection hurdles, a sampling frame of 1566 potential operator applicants remained within the databank. Given that the sampling frame was readily available to the researcher, a non-probability convenience sampling technique was employed, thus utilising the entire sampling frame within this study.

The majority $(65.7 \%)$ of this study's sample was male. A significant portion $(45.3 \%)$ of the study's participants were aged between 25 and 29 years, with the second largest group $(22.8 \%)$ of respondents within the 30- to 34-year age category. Over $80 \%$ of the candidates surveyed were black candidates, $16.8 \%$ were mixed race, $0.5 \%$ were Indian and $0.9 \%$ were white candidates. A sizeable proportion (44.4\%) of the sample have achieved an academic-type secondary education with mathematics and science as subjects. The second highest category $(25.1 \%)$ was the general academic-type of matriculation with neither mathematics nor science as subjects in Grade 12. Applicants who completed their 
academic Grade 12 qualification with mathematics as a subject were the third highest category at $19.2 \%$. A technicaltype matriculation, inclusive of mathematics and science as subjects, was completed by $7.3 \%$ of the sample. The remaining $3.9 \%$ of the candidates had completed an academic Grade 12 with science as a subject.

Of the 2463 respondents who completed the first selection phase, 1618 were successful in meeting the qualifying screening criterion set for this phase and were therefore invited to attend the second phase of the selection process. A total of 49 candidates, evenly spread across all groups, were lost because of attrition for a variety of reasons prior to the commencement of the second phase of the assessment process. Therefore, a total of 1569 applicants were expected to complete phase two of the assessment process. However, three candidates were requested to exit the assessment process because they did not adhere to the prescribed assessment regulations. Consequently, a total number of 1566 respondents (63.6\%) were actually assessed in the second phase of the assessment process. This was conducted over six assessment sessions.

\section{Measuring instruments}

Trade Aptitude Test Battery: The aim of the Trade Aptitude Test (TRAT) battery is to assist in the selection of potential students for admittance into technical institutes and colleges. The test battery also indicates the candidates' potential to progress and successfully finish training in a specific technical field (Taljaard, 1983). The authors used five sub-tests from the TRAT battery to ascertain the identified technically specified aptitudes required for the automotive operator position. The key differences with regard to purpose, items per instrument and time limits of these sub-tests are discussed.

The dexterity sub-test: This tool determines an aspect of the candidate's two-hand eye coordination, a facet of psychomotor coordination. The sub-test is based on the postulation that the capacity to simultaneously, rapidly and accurately pencil in circles, by employing a pencil in each hand, between the provided pairs of concentric circles is a valid indicator of two-hand-eye coordination. The instrument consists of 72 items with a 2-min test completion time (Taljaard, 1983).

The coordination sub-test: The intention of this sub-test is to establish the candidate's hand-eye coordination, another facet of psychomotor ability. The test rests on the hypothesis that the skill required to pencil in an unbroken line rapidly and precisely, by hand, between circular zones by going above one and below the other, without contacting the zones or picking up one's pencil, is regarded as a valid gauge of hand-eye coordination. Two minutes are allowed to attempt 127 items in this sub-test (Taljaard, 1983).

The assembly sub-test: The aim of this sub-test is to reveal the candidate's ability to build illustrations mentally of mechanical parts to shape a provided mechanical object. The rationale is that the candidate's ability to assemble mentally representations of parts of a mechanical nature on the basis of fixed regulations is regarded to be a valid measurement of his/her ability to assemble mechanical components. This sub-test comprises 25 multiple-choice type questions and a time limit of $25 \mathrm{~min}$ (Taljaard, 1983).

The spatial perception 2-D sub-test: This sub-test seeks to disclose the candidate's two-dimensional spatial perceptual ability. The test rests on the assumption that the degree to which a candidate sees 2-D geometrical shapes and is able to mentally rotate them on a flat surface is regarded to be a valid measurement of 2-D spatial perceptual ability. The sub-test comprises multiple-choice type questions with a time limit of 17 min for completion (Taljaard, 1983).

The spatial perception 3-D sub-test: This instrument is aimed at determining the candidate's three-dimensional spatial perceptual ability. This test rests on the assumption that the degree to which a candidate is able to visualise mentally, turn and merge 3-D figures, in order to formulate them to appear similar to a given representation and to shape mentally a 3-D composition from a 2-D plan, is a valid measurement of his or her 3-D spatial perceptual ability. This tool consists of two sections: Section (1) comprises 13 multiple-choice type questions to be attempted in $7 \mathrm{~min}$; Section (2) has 12 multiple-choice type questions to be completed in 9 min (Taljaard, 1983).

The reliability of the various sub-tests within the TRAT battery was determined by the Kuder-Richardson formula 21 (K-R 21). The reliability coefficients of three of the TRAT sub-tests used in this study, namely the assembly, spatial perception 2-D and 3-D sub-tests, range from 0.72 to 0.92 and are regarded as being satisfactory. The dexterity and coordination measures are speed tests and the K-R 21 formula is therefore not applicable (Taljaard, 1983). With regards to the validity of the TRAT battery, the test manual indicates that no validity data were available at the time of printing. There is also a risk of restriction of range because of the potential lack of sensitivity of the instrument, which should be noted. However, the TRAT battery is a registered and approved psychological test by the Health Professions Council of South Africa and on this basis it was decided to continue using this instrument within the research study.

\section{Research procedure and ethical considerations}

Data were collected over a period of several months. Following an in-house initial pre-screening process, candidates were required to participate in a multiplehurdle selection process comprising two assessment phases. Those successful in phase 1, the general aptitude tools, were requested to complete phase 2, the technical aptitude sub-tests.

Answer sheets were manually scored using a scoring stencil, except for the dexterity and coordination measures, which were scored according to the psychological test manuals' scoring 
instructions. In adherence to standard psychometric assessment practice, raw scores were converted to stanines, using the Grade 8 to Grade 10 norm table. This is in line with previous research done in the field (Lohman \& Lakin, 2009; Strand, Deary \& Smith, 2006; Stromso, Bråten \& Samuelstuen, 2003). The stanine scores were then captured onto a Microsoft Excel ${ }^{\circledR}$ spreadsheet and imported into SPSS to be analysed statistically.

\section{Statistical analysis}

Statistical analysis of the data was conducted using the SPSS 20 statistical package. Descriptive and inferential statistics were calculated. The descriptive statistics were intended to present a snapshot of the data, and the Chi-square test of independence was used to evaluate the relationship between secondary education (incorporating subject choice) and the five aptitudes assessed.

In preparation for the execution of the inferential statistics, the aptitude sub-tests results were tabulated into three categories: a low-, moderate- and high-scoring category. The low-scoring category included stanine scores ranging from 1 to 3 , the moderate category comprised the stanine scores 4 to 6 , whilst the stanine scores 7 to 9 were designated to the high-scoring category. Inferential statistics were then performed on these three scoring categories. Bivariate statistical analysis was carried out on the two variables within each hypothesis to establish either covariance or independence between the dependent and independent variables (Bryman \& Bell, 2011). In this study, the dependent variables were the five aptitudes assessed and the independent variable was the type of secondary education (incorporating subject choice) obtained. To test the significance of the relationship between the variables for the five hypotheses, the Chi-square test of independence was used. An alpha level of 0.05 was used for each of these statistical tests. The null hypotheses were not rejected if there was independence between the variables, whilst the alternate hypotheses were acknowledged if there was covariation between the dependent and independent variables. In order to elucidate the magnitude of the relationship between the variables, effect size statistics were employed and interpreted. Informed judgements of the study's practical significance of the relationships were hence made possible (Sun, Pan \& Wang, 2010). The Cramér's $V$ statistic was reported in the analyses of the hypotheses and interpreted according to the eta-squared guidelines.

\section{Ethical consideration}

Permission was obtained from the automotive plant's head office to collect data in the organisation. All research respondents were also thoroughly informed of the assessment process and each participant voluntarily completed a specifically designed informed consent form.

\section{Results}

\section{Descriptive statistics}

Table 1 displays the descriptive statistics for the five aptitude sub-tests. The 2-D and 3-D spatial perception tools recorded the highest medians at seven, being in the high range. The
TABLE 1: Medians and modes of Trade Aptitude Test Battery sub-tests.

\begin{tabular}{lcc}
\hline Sub-tests & Mdn & Mo \\
\hline Dexterity & 3 & 3 \\
Coordination & 5 & 5 \\
Assembly & 6 & 6 \\
Spatial perception 2-D & 7 & 9 \\
Spatial perception 3-D & 7 & 7 \\
\hline
\end{tabular}

Mdn, median; Mo, mode.

Note: The distribution of the data is recorded in stanine format.

medians for the assembly and coordination sub-tests were within the moderate range, being six and five, respectively. The lowest median, three, was found for the dexterity measure. The highest mode, nine, was established for the spatial perception 2-D sub-test, with the second highest mode, being seven, recorded for the spatial perception 3-D instrument. The mode for the assembly sub-test was six, whilst a mode of five was documented for the coordination sub-test. The mode for the dexterity sub-test was the lowest at three.

\section{Inferential statistics}

Chi-square tests of independence were completed to scrutinise the relationship between the form of secondary education (incorporating subject choice) and the stanine scores achieved in the five aptitude tests, grouped according to low, moderate and high scores. Tables 2 through 6 provide a synopsis of the results obtained by the applicants $(N=1566)$ in the five aptitude measures according to the form of secondary education obtained (incorporating subject choice).

Hypothesis 1: There is a significant relationship between levels of dexterity and type of secondary education qualification (incorporating subject choice) obtained.

The data provided in Table 2 show that the type of matriculation (incorporating subject choice) education obtained was significantly related to the dexterity sub-test scores. The relationship between these two variables was statistically significant, $X^{2}(8, n=1566)=17.94, p<0.05$. The $p$-value was 0.022 , which is less than the significance level of 0.05 .

Table 2 also illustrates that low stanine scores on the dexterity tool were associated with the technical and general Grade 12 qualifications. Moderately high scores were obtained by $39 \%$ of the general type secondary education in this sub-test with only $38 \%$ of the technical matriculation group achieving the same moderate scores. On the other hand, moderate scores were attained by candidates with mathematics (51\%) or science $(54 \%)$ as a subject in their secondary education. Respondents with mathematics and science as matric subjects (54\%) scored low and $45 \%$ scored at a moderate level on the dexterity sub-test. High scores in this measure were only achieved by $1 \%$ of the total sample of applicants.

Hypothesis 1 was therefore accepted.

Hypothesis 2: There is a significant relationship between levels of coordination and type of secondary education qualification (incorporating subject choice) obtained.

The study's second null hypothesis stated that there would not be a significant relationship between levels of coordination 
and type of secondary education qualification (incorporating subject choice) obtained. However, as depicted in Table 3, the relationship between the type of secondary education and the coordination of stanine scores was statistically significant, $X^{2}(8, n=1566)=16.02, p<0.05, V=0.06$. The significant correlation coefficient for this relationship was found to be 16.02 and the $p$-value was significant at 0.042 . The moderate practical significance of this hypothesis was established through the Cramér's $V$ statistic. The effect size (0.06) for this finding was medium, thereby elucidating the judicious strength of association between the two variables in this hypothesis (Pallant, 2013).

Seventy per cent of the respondents with mathematics and science as matric subjects and a general type of secondary education obtained moderate scores in this instrument. A total of $89 \%$ of these two forms of qualifications achieved moderate to high category scores. Candidates with mathematics as a subject in their Grade 12 qualification achieved the largest percentage $(23 \%)$ in the high-scoring category. However, Table 3 also highlights that the majority (69\%) of applicants with this type of Grade 12 qualification realised moderate scores. Applicants with science as a subject in their secondary education mostly (69\%) achieved moderate scores in demonstrating this aptitude. A technical-type matriculation obtained the highest percentage (19\%) in the low-stanine score category.

Hypothesis 2 was therefore accepted.

\section{Hypothesis 3: There is a significant relationship between assembly scores and type of secondary education qualification (incorporating subject choice) obtained.}

A significant relationship $-X^{2}(8, n=1566)=44.59, p<0.05$, $V=0.10$ - was established between the type of Grade 12 qualification (incorporating subject choice) held and the assembly sub-test stanine scores as displayed in Table 4 . The relationship between these variables was characterised by a high, significant correlation coefficient of 44.59 and a $p$-value of 0.0001 at a $95 \%$ confidence interval. Furthermore, the strength of the association between the variables was large $(V=0.10)$, highlighting the sizeable practical significance of this hypothesis' findings (Pallant, 2013).

Stanine scores in the high category were associated with candidates who had obtained a matriculation education with

TABLE 2: Contingency table of observed frequencies for the dexterity sub-test.

\begin{tabular}{|c|c|c|c|c|c|c|c|}
\hline \multirow[t]{2}{*}{ Dexterity } & \multirow[t]{2}{*}{ Stanine scores } & \multicolumn{5}{|c|}{ Type of secondary education } & \multirow[t]{2}{*}{ Tota } \\
\hline & & Mathematics and science & Mathematics & Science & Technical & General & \\
\hline \multirow[t]{2}{*}{ Low } & Count & 389 & 162 & 27 & 64 & 205 & 847 \\
\hline & $\%$ within group & 54 & 49 & 46 & 62 & 60 & 54 \\
\hline \multirow[t]{2}{*}{ Moderate } & Count & 329 & 170 & 32 & 39 & 133 & 703 \\
\hline & $\%$ within group & 45 & 51 & 54 & 38 & 39 & 45 \\
\hline \multirow[t]{2}{*}{ High } & Count & 8 & 1 & 0 & 1 & 6 & 16 \\
\hline & $\%$ within group & 1 & 0 & 0 & 0 & 1 & 1 \\
\hline \multirow[t]{2}{*}{ Total } & Count & 726 & 333 & 59 & 104 & 344 & 1566 \\
\hline & $\%$ within group & 100 & 100 & 100 & 100 & 100 & 100 \\
\hline
\end{tabular}

Note: $X^{2}(8, n=1566)=17.943, p<0.05$.

TABLE 3: Contingency table of observed frequencies for the coordination sub-test.

\begin{tabular}{|c|c|c|c|c|c|c|c|}
\hline \multirow[t]{2}{*}{ Coordination } & \multirow[t]{2}{*}{ Stanine scores } & \multicolumn{5}{|c|}{ Type of secondary education } & \multirow[t]{2}{*}{ Total } \\
\hline & & Mathematics and science & Mathematics & Science & Technical & General & \\
\hline \multirow[t]{2}{*}{ Low } & Count & 80 & 24 & 5 & 20 & 37 & 166 \\
\hline & $\%$ within group & 11 & 7 & 8 & 19 & 11 & 11 \\
\hline \multirow[t]{2}{*}{ Moderate } & Count & 507 & 231 & 41 & 70 & 240 & 1089 \\
\hline & $\%$ within group & 70 & 69 & 69 & 67 & 70 & 70 \\
\hline High & Count & 139 & 78 & 13 & 14 & 67 & 311 \\
\hline \multirow[t]{2}{*}{ Total } & Count & 726 & 333 & 59 & 104 & 344 & 1566 \\
\hline & $\%$ within group & 100 & 100 & 100 & 100 & 100 & 100 \\
\hline
\end{tabular}

Note: $X^{2}(8, n=1566)=16.02, p<0.05, V=0.06$.

TABLE 4: Contingency table of observed frequencies for the assembly sub-test.

\begin{tabular}{|c|c|c|c|c|c|c|c|}
\hline \multirow[t]{2}{*}{ Assembly } & \multirow[t]{2}{*}{ Stanine scores } & \multicolumn{5}{|c|}{ Type of secondary education } & \multirow[t]{2}{*}{ Total } \\
\hline & & Mathematics and science & Mathematics & Science & Technical & General & \\
\hline \multirow[t]{2}{*}{ Low } & Count & 36 & 20 & 1 & 5 & 29 & 91 \\
\hline & $\%$ within group & 5 & 6 & 2 & 5 & 8 & 6 \\
\hline \multirow[t]{2}{*}{ Moderate } & Count & 317 & 143 & 29 & 49 & 205 & 752 \\
\hline & $\%$ within group & 44 & 43 & 49 & 58 & 60 & 48 \\
\hline \multirow[t]{2}{*}{ High } & Count & 373 & 170 & 29 & 49 & 110 & 723 \\
\hline & $\%$ within group & 51 & 51 & 49 & 41 & 32 & 46 \\
\hline \multirow[t]{2}{*}{ Total } & Count & 726 & 333 & 59 & 104 & 344 & 1566 \\
\hline & $\%$ within group & 100 & 100 & 100 & 100 & 100 & 100 \\
\hline
\end{tabular}

Note: $X^{2}(8, n=1566)=44.59, p<0.05, V=0.10$. 
either mathematics and science or just mathematics as subjects. For both types of secondary education, more than half $(51 \%)$ of the applicants attained high stanine scores. Ninety-eight per cent of the candidates with a Grade 12 qualification inclusive of science attained stanine scores of four and above for this tool. However, as depicted in Table 4, candidates who held a technical or a general Grade 12 qualification achieved a higher percentage (58\% and 60\%, respectively) in the moderate stanine category than candidates with the other types of secondary education. More than $90 \%$ of the respondents with the secondary education types inclusive of both mathematics and science and the technical Grade 12 qualification attained moderateto high category scores.

Hypothesis 3 was therefore accepted.

\section{Hypothesis 4: There is a significant relationship between spatial perception (2-D) and type of secondary education qualification (incorporating subject choice) obtained.}

There was a significant relationship between the type of secondary education (incorporating subject choice) and the spatial perception 2-D sub-test stanine scores, $X^{2}(8, n=1566)=39.83$, $p<0.05, V=0.09$. The $p$-value $(0.001)$ was less than the significance level of 0.05 ; hence, the null hypothesis was rejected on the basis that the two variables are statistically related. Furthermore, the Cramér's $V$ statistic $(V=0.09)$ revealed a large effect size, highlighting the considerable practical significance of this finding (Pallant, 2013).

Table 5 highlights that applicants with either mathematics and science or just mathematics as subjects in their Grade 12 qualification obtained higher scores $(57 \%$ and $56 \%$, respectively) than candidates with the other types of secondary education. Ninety per cent or more of the respondents with mathematics or mathematics and science or a technical Grade 12 qualification attained moderate- to high-level scores. Slightly less than half $(46 \%)$ of the respondents with science as a Grade 12 subject achieved high stanine scores. The general type of matriculation group attained the largest percentage (19\%) in the low-stanine score category.

Hypothesis 4 was therefore accepted.

Hypothesis 5: There is a significant relationship between levels of spatial perception (3-D) and type of secondary education (incorporating subject choice) qualification obtained.

Table 6 provides the data supporting the relationship between the type of Grade 12 qualification (incorporating subject choice) and the spatial perception 3-D sub-test stanine scores. This relationship was statistically and practically significant, $X^{2}(8, n=1566)=46.96, p<0.05, V=0.10$. The effect size between the dependent and independent variables in this hypothesis was regarded as large and hence contextualises the importance of this hypothesis' findings (Pallant, 2013).

More respondents with mathematics as a matric subject realised higher scores $(65 \%)$ in this instrument than candidates with the other types of secondary education. The second highest percentage (59\%) of high-stanine category scores was obtained by candidates with mathematics and science as subjects in their secondary education. Table 6 also highlights that those with a Grade 12 qualification with science as a subject achieved a larger percentage (49\%) of moderate stanine category results in comparison to those with the other types of secondary education. Just under half of the respondents with this type of matriculation also realised high stanine scores in this measure. The technical

TABLE 5: Contingency table of observed frequencies for the spatial perception 2-D sub-test.

\begin{tabular}{|c|c|c|c|c|c|c|c|}
\hline \multirow{2}{*}{$\begin{array}{l}\text { Spatial perception } \\
\text { 2-D }\end{array}$} & \multirow[t]{2}{*}{ Stanine scores } & \multicolumn{5}{|c|}{ Type of secondary education } & \multirow[t]{2}{*}{ Total } \\
\hline & & Mathematics and science & Mathematics & Science & Technical & General & \\
\hline \multirow[t]{2}{*}{ Low } & Count & 66 & 27 & 8 & 11 & 64 & 170 \\
\hline & $\%$ within group & 8 & 8 & 14 & 11 & 19 & 11 \\
\hline \multirow[t]{2}{*}{ Moderate } & Count & 251 & 119 & 24 & 38 & 136 & 568 \\
\hline & $\%$ within group & 35 & 36 & 41 & 37 & 40 & 36 \\
\hline \multirow[t]{2}{*}{ High } & Count & 415 & 187 & 27 & 55 & 144 & 828 \\
\hline & $\%$ within group & 57 & 56 & 46 & 53 & 42 & 53 \\
\hline \multirow[t]{2}{*}{ Total } & Count & 726 & 333 & 59 & 104 & 344 & 1566 \\
\hline & $\%$ within group & 100 & 100 & 100 & 100 & 100 & 100 \\
\hline
\end{tabular}

Note: $X^{2}(8, n=1566)=39.83, p<0.05, V=0.09$.

TABLE 6: Contingency table of observed frequencies for the spatial perception 3-D sub-test.

\begin{tabular}{|c|c|c|c|c|c|c|c|}
\hline \multirow{2}{*}{$\begin{array}{l}\text { Spatial perception } \\
\text { 3-D }\end{array}$} & \multirow[t]{2}{*}{ Stanine scores } & \multicolumn{5}{|c|}{ Type of secondary education } & \multirow[t]{2}{*}{ Total } \\
\hline & & Mathematics and science & Mathematics & Science & Technical & General & \\
\hline \multirow[t]{2}{*}{ Low } & Count & 37 & 11 & 1 & 9 & 32 & 90 \\
\hline & $\%$ within group & 5 & 3 & 2 & 9 & 9 & 6 \\
\hline \multirow[t]{2}{*}{ Moderate } & Count & 258 & 106 & 29 & 44 & 169 & 600 \\
\hline & $\%$ within group & 36 & 32 & 49 & 42 & 47 & 38 \\
\hline \multirow[t]{2}{*}{ High } & Count & 431 & 216 & 29 & 51 & 149 & 876 \\
\hline & $\%$ within group & 59 & 65 & 49 & 49 & 43 & 56 \\
\hline \multirow[t]{2}{*}{ Total } & Count & 726 & 333 & 59 & 104 & 344 & 1566 \\
\hline & $\%$ within group & 100 & 100 & 100 & 100 & 100 & 100 \\
\hline
\end{tabular}

Note: $X^{2}(8, n=1566)=46.96, p<0.05, V=0.10$. 
and general types of matriculants were also associated with moderate to high stanine scores. Of the 344 respondents with a general Grade 12 qualification, 318 obtained stanine scores of four and above.

Based on the results, Hypothesis 5 was therefore accepted.

\section{Discussion}

The primary objectives of this study were to investigate the relationship between hand-eye coordination test scores and types of secondary education (incorporating subject choice) and to determine whether the forms of secondary education (incorporating subject choice) were related to the spatial visualisation test scores.

\section{Outline of the results}

Three conclusions have been derived from the study's five hypotheses. The first conclusion points to a differing complexity level across the five instruments employed in this study, whilst the second and third conclusions outline the different levels of aptitudes presented by matriculants with different types of secondary education.

In Table 1, which summarised the distribution of the five aptitude sub-tests, the increased intensity of exertion is clearly evident from the wide frequency distribution across the stanine scores of the five tools. The median and mode for the dexterity measure, which assessed the respondents' twohand-eye coordination, is significantly below those of the other four tools. These two central tendency measures place the results for this sub-test in the below-average category, indicating that the majority of the respondents would be outperformed by at least $77 \%$ of the SA population in this aptitude. The median and mode for the one-hand-eye coordination instrument was slightly higher than that obtained for the dexterity sub-test. The three measures of spatial visualisation realised central tendency stanine scores in the high-average to superior range. Thus, it is concluded that the respondents found the two psychomotor tools more challenging than the three spatial visualisation techniques. Previous research has offered two explanations for this lower ability on high-speed aptitude tests. Firstly, because of outcomes-based education, SA students tend to be less speed oriented (Van der Merwe, 2008). Secondly, the maintenance of selective attention in the youth has been radically reduced because of the continuous over-stimulation offered by readily available entertainment (Cocodia et al., 2003).

The second conclusion pertains to the endorsed types of secondary education. Based on the results obtained across the five aptitude measures, three forms of secondary education (incorporating subject choice) are recommended, namely a Grade 12 qualification inclusive of science; a matriculation education with mathematics as a subject; and a secondary education including both mathematics and science subjects. The applicants with the secondary education inclusive of science consistently outperformed the other applicants educated through matriculation type in three of the instruments, namely, dexterity, assemble and spatial perception 3-D. However, in two of the subtests, namely coordination and spatial perception 2-D, they were outperformed. Matriculants who studied mathematics and/or science performed consistently better in the five aptitude sub-tests in comparison to the other two types of secondary education. These three forms of secondary education are concluded to have been positively associated with the applicants' accomplishments in these specific aptitude measures. These forms of Grade 12 qualifications may also have afforded the applicants with exposure to a spatially enriched education as described in the research by Hsi et al. (1997), Stieff et al. (2013) and Uttal et al. (2013a). This conclusion is in line with previous research which established that enhanced spatial ability is significantly associated with accomplishment in STEM domains (Humphreys et al., 1993; Kell \& Lubinski, 2013; Shea et al., 2001).

Thirdly, the technical and general types of secondary education were not optimal performers in the five aptitude sub-tests. Whilst the technical matriculation applicants performed moderately well in the assembly and spatial perception 2-D sub-tests, they did not perform optimally in the other three sub-tests. It is therefore concluded that these two forms of matriculation (incorporating subject choice) education are not able to reliably provide the technically oriented abilities required of automobile operators. This confirms the abundance of literature indicating the educational crisis that is being experienced in the technical school system, both internationally and nationally. Improved technical training systems should assist in addressing the current technical skills gaps by focusing on the type, relevance and levels of courses being offered (Ramdass, 2009; Spaull, 2013; Van der Berg, Taylor, Gustafsson, Spaull \& Armstrong, 2011; Van de Werfhorst, 2014). This study has emphasised the challenges faced by national FET institutions (Department: Higher Education and Training, 2014; Manuel, 2011; Nzimande, 2010). Whilst a high demand for learning opportunities exists within the SA youth, FET colleges have not been successful in enticing this portion of the population to participate in their programmes. This may be because of the weak relationships between FET colleges and the workplace, which culminates in unsuitable types and levels of training (Manuel, 2011).

Overall, the results of this study have highlighted statistically significant relationships between the five technically oriented aptitudes assessed in this study and the type of secondary education (incorporating subject choice) attained. This finding supports previous research that has highlighted the need for changes in curriculum design, teaching and assessment methodologies currently being employed in certain forms of secondary education. Being exposed, through certain forms of schooling, to specific stimuli and activities may have significant associations with specific abilities and hence potential employability. 


\section{Practical implications}

The contribution of this research study is three-fold. The study has confirmed the applicability and relevance of employing the type of secondary education (incorporating subject choice) obtained as a cost-effective screening tool. Human resource practitioners need to take cognisance of the warning provided by several academics and researchers regarding the poor quality of education stemming from certain forms of secondary education in the country (Ramdass, 2009; Spaull, 2013; Van der Berg et al., 2011; Van de Werfhorst, 2014). Technical high schools and FET institutions need to review their current offerings in order to equip students adequately with the specific aptitudes required within the automotive industry. Candidates with a technicaltype secondary education performed inadequately in the two psychomotor and spatial perception 3-D sub-tests in comparison to the other four forms of matriculation. Technical training and education providers need to address these specific areas in their future offerings. Open discussions with the broader manufacturing sector may assist in improving understanding of the industry's requirements.

Secondly, the study has provided SA research confirming a relationship between education, training and specific cognitive abilities. This is of particular importance given the documented association between spatial aptitudes and achievement in STEM fields. Thirdly, this study's findings have highlighted the benefits of utilising a multiple rather than a singular selection methodology. This is highly relevant in the SA context where supply exceeds demand in the labour market.

\section{Limitations and recommendations}

This study's sample is not in line with either provincial or national data pertaining to age, race or gender as indicated in the 2001 census (Lehohla, 2004). Furthermore, this study was part of a sizeable recruitment process implemented by a SA automotive assembly plant with the sampling frame for this study being a database of pre-screened potential operators. Therefore, the main inadequacy of this research is that the results cannot be generalised to either the SA or global automobile industry. The second limitation of the study relates to the scores obtained by the applicants in their secondary education qualifications, both overall and for specific subjects. This was delineated out of the study's scope but it is plausible that the sample constituting the technical and general types of secondary education was not of an adequate calibre. This should be explored in future research. It is also recommended that future studies explore the relationship between the types of secondary education and employability as conducted by Shea et al. (2001) and/or onthe-job performance ratings.

\section{Conclusion}

The primary objective of the study was to investigate the relationship between the type of secondary education (incorporating subject choice) obtained and the spatial and psychomotor aptitudes of potential operators within the automotive industry. The key variable to ascertain this relationship was a psychological assessment tool. The central recommendation from this research counsels the automotive industry to focus on applicants with mathematics and/or science as subjects in their academic Grade 12 qualification. The study has confirmed the utility of employing type of secondary education (incorporating subject choice) as a costeffective initial screening mechanism within a multiplehurdle selection approach. This has value for human resource managers and practitioners who are seeking to optimise the STEM fields within their organisation whilst not being overly burdened with compliance to the rules and regulations associated with psychological testing.

\section{Acknowledgements}

This research study formed part of a large recruitment process completed by a South African automotive assembly plant. The administration and communication of this research study was conducted by the internal human resource project team.

\section{Competing interests}

The authors declare that they have no financial or personal relationship(s) that may have inappropriately influenced them when they wrote this article

\section{Authors' contributions}

N.D. and K.V. were the promoters of J.P. for her master's dissertation. The article flows from her research in this regard.

\section{References}

Adanez, G.P. (2004). Training visualization ability by technical drawing. Journal for Geometry and Graphics, 8(1), 107-115.

Adanez, G.P., \& Velasco, A.D. (2002). Predicting academic success of engineering students in technical drawing from visualization test scores. Journal for Geometry and Graphics, 6(1), 99-109.

Ajith, P. (2015). KESHAVA - Holistic employee selection in the VUCA world. SCMS Journal of Indian Management, 12(4), 5-18.

Akinyemi, G.M., \& Abiddin, N.Z. (2013). Human capital developments an interdisciplinary approach for individual, organisational advancement and economic improvement. Asian Social Science, 9(4), 150-157. https://doi. org/10.5539/ass.v9n4p150

Bennett, N., \& Lemoine, G.J. (2014). What VUCA really means for you. Harvard Business Review, 92(1), 27-37.

Bordelon, V.P., \& Kantor, J.E. (1986). Utilization of Psychomotor Screening for USAF Pilot Candidates: Independent and Integrated Selection Methodologies. Final Report for Period March 1978-August 1984. Brooks AFB, TX: Air Force Human Resources Lab.

Brinch, C.N., \& Galloway, T.A. (2011). Schooling in adolescence raises IQ scores. Proceedings of the National Academy of Sciences, 109(2), 425-430. https://doi. org/10.1073/pnas.1106077109

Brown, H. (2013). Artisan development unit. Retrieved June 02, 2016, from http://www. merseta.org.za/Innovation, ResearchandDevelopment/ArtisanDevelopment.aspx/

Bryman, A. (2012). Social research methods. (4th edn.). New York: Oxford University Press.

Bryman, A., \& Bell, E. (2011). Business research methods. (3rd edn.). New York: Oxford University Press.

Carlsson, M., Dahl, G.B., Öckert, B., \& Rooth, D. (2015). The effect of schooling on cognitive skills. The Review of Economics and Statistics, 97(3), 533-547. https:// doi.org/10.1162/REST_a_00501

Carretta, T.R., \& Ree, M.J. (1997). Expanding the nexus of cognitive and psychomotor abilities. International Journal of Selection and Assessment, 5, 149-158. https:// doi.org/10.1111/1468-2389.00055 
Carretta, T.R., \& Ree, M.J. (2000). General and specific cognitive and psychomotor abilities in personnel selection: The prediction of training and job performance. International Journal of Selection \& Assessment, 8(4), 227-236. https://doi. International Journal of Selection
org/10.1111/1468-2389.00152

Carroll, J.B. (1993). Human cognitive abilities: A survey of factor-analytic studies. New York: Cambridge University Press.

Cattell, R.B. (1963). The theory of fluid and crystallized intelligence: A critical experiment. Journal of Educational Psychology, 54, 1-22. https://doi.org/10.1037/ h0046743

Chaiken, S.R., Kyllonen, P.C., \& Tirre, W.C. (2000). Organization and components of psychomotor ability. Cognitive Psychology, 40, 198-226. https://doi.org/10.1006/ cogp.1999.0729

Christensen, R., Knezek, G., \& Tyler-Wood, T. (2015). Alignment of hands-on STEM engagement activities with positive STEM dispositions in secondary school students. Journal of Science Education and Technology, 24(6), 898-909. https:// doi.org/10.1007/s10956-015-9572-6

Cocodia, E.A., Kim, J.S., Shin, H.S., Kim, J.W., Ee, J., Wee, M.S.W., et al. (2003). Evidence that rising population intelligence is impacting in formal education. Personality
and Individual Differences, 35, 797-810. https://doi.org/10.1016/s0191and Individual

Cosser, M., \& Sehlola, S. (2009). Ambitions revised: Grade 12 learner destinations one year on. Retrieved May 26, 2016, from http://www.hsrcpress.ac.za/product.php? cat $=29 \&$ freedownload $=1$ \& productid $=2266$;

Deloitte. (2009). A new era: Accelerating toward 2020 - An automotive industry transformed. Retrieved June 02, 2016, from http://www.deloitte.com/assets/ Dcom-SouthAfrica.pdf/

Department: Higher Education and Training. (2014). National Skills Development Strategy 111: Progress report 2011-2013. Retrieved June 02, 2016, from http:// www.dhet.gov.za/LinkClick.aspx?fileticket=AOv8W\%2Bm3xHI\%3D\&tabid=1131

Douglas, O., Burton, K.S., \& Reese-Durham, N.R. (2008). The effects of the multiple intelligence teaching strategy on the academic achievement of eighth grade math students. Journal of Instructional Psychology, 35, 182-187.

Ekinci, B. (2014). The relationships among Sternberg's triarchic abilities, Gardner's multiple intelligences and academic achievement. Social Behaviour and Personality, 42(4), 625-634. https://doi.org/10.2224/sbp.2014.42.4.625

Foxcroft, C., \& Roodt, G. (2013). Introduction to psychological assessment in the South African context. (4th edn.). Cape Town: Oxford University Press.

Furnham, A. (2008). Personality and intelligence at work: Exploring and explaining individual differences at work. New York: Routledge.

Gallagher, A.G., Leonard, G., \& Traynor, O.J. (2009). Role and feasibility of psychomotor and dexterity testing in selection for surgical training. Surgical Education, 79 108-113. https://doi.org/10.1111/j.1445-2197.2008.04824.x

Gansky, S.A., Pritchard, H., Kahl, E., Mendoza, D., Bird, W., Miller, A.J., et al. (2004). Reliability and validity of a manual dexterity test to predict preclinical grades. Journal of Dental Education, 68(9), 985-994.

Gardner, H. (1983). Frames of mind: The theory of multiple intelligences. New York: Basic Books.

Gardner, H. (1999). Intelligence reframed. New York: Basic Books.

Hall, C., Dickerson, J., Batts, D., Kauffmann, P., \& Bosse, M. (2011). Are we missing opportunities to encourage interest in STEM fields? Journal of Technology Education, 23(1), 32-46. https://doi.org/10.21061/jte.v23i1.a.4

Harlan, J. (2014). Asprin, Aspirations and the ABCs: Why America needs more STEM workers. Retrieved May 26, 2016, from http://0-eds.a.ebscohost.com.wam.seals. ac.za/eds/pdfviewer/pdfviewer?sid=ca0880d4-0004-410a-a438-0f43d65f14a9\% 40sessionmgr4010\&vid=1\&hid $=4108$

Horn, J.L. (1976). Human abilities: A review of research and theory in the early 1970's. Annual Review of Psychology, 27, 437-485. https://doi.org/10.1146/annurev. Annual Review of Psych
ps.27.020176.002253

Hsi, S., Linn, M.C., \& Bell, J.E. (1997). The role of spatial reasoning in engineering and the design of spatial instruction. Journal of Engineering Education, April, 151-158. https://doi.org/10.1002/j.2168-9830.1997.tb00278.x

Humphreys, L.G. (1962). The organization of human abilities. American Psychologist, 17, 475-483. https://doi.org/10.1037/h0041550

Humphreys, L.G., Lubinski, D., \& Yao, G. (1993). Utility of predicting group membership and the role of spatial visualization in becoming an engineer, physical scientist, or artist. Journal of Applied Psychology, 78(2), 250-261. https://doi.org/10.1037/ 0021-9010.78.2.250

Hunt, E. (2014). Teaching intelligence: Why, why it is hard and perhaps how to do it. Intelligence, 42, 156-165. https://doi.org/10.1016/j.intell.2013.06.018

Hunter, J.E., \& Hunter, R.F. (1984). Validity and utility of alternative predictors of job performance. Psychological Bulletin, 96, 72-98. https://doi.org/10.1037/00332909.96.1.72

Inskeep, G.C. (1971). The use of psychomotor tests to select sewing machine operators Some negative findings. Personnel Psychology, 24(4), 707-714. https://doi.org/ 10.1111/j.1744-6570.1971.tb00384.x

Jankowicz, A.D. (2005). Business research projects. (4th edn.). Croatia: South-Western Cengage Learning.

Johnson, W., \& Bouchard, T. J. (2005). The structure of human intelligence: It is verbal, perceptual, and image rotation (VPR), not fluid and crystallized. Intelligence, 33 393-416. https://doi.org/10.1016/j.intell.2004.12.002

Johnson, W., Nijenhuis, J., \& Bouchard, T.J. (2007). Replication of the hierarchical visual-perceptual-image rotation model in de Wolff and Buiten's (1963) battery if 46 tests of mental ability. Intelligence, 35, 69-81. https://doi.org/10.1016/j. intell.2006.05.002
Kell, H.J., \& Lubinski, D. (2013). Spatial ability: A neglected talent in educational and occupational settings. Roeper Review, 35, 219-230. https://doi.org/10.1080/0278 3193.2013.829896

Kuncel, N.R., \& Hezlett, S.A. (2010). Fact and fiction in cognitive ability testing for admissions and hiring decisions. Current Directions in Psychological Science, 19(6), 339-345. https://doi.org/10.1177/0963721410389459

Lehohla, P. (2004). Post-enumeration survey: Results and methodology. Retrieved May 26, 2016, from http://www.statssa.gov.za/census01/html/pes.pdf

Lehohla, P. (2010). Education does matter. Retrieved June 02, 2016, from http://www. statssa.gov.za/news_archive/SG8November2010_1.asp/

Lohman, D.F. \& Lakin, J.M. (2009). Consistencies in sex differences on the Cognitive Abilities Test across countries, grades, test forms, and cohorts. British Journal of
EducationalPsychology, 79(2),389-407.https://doi.org/10.1348/000709908X354609

Mahembe, E. (2012). AATP post trade test tracer study: Final Report. Prepared by Underhill Corporate Solutions. Retrieved May 26, 2016, from http://www. merseta.org.za/artisandevelopment.asp/

Manuel, T. (2011). National development plan: Vision for 2030. Retrieved May 28, 2016, from http://www.npconline.co.za/medialib/downloads/home/NPC\%20 National\%20Development $\% 20$ Plan $\% 20$ Vision $\% 202030 \% 20$-lo-res.pdf/

Mayer, M.J., Gordhan, S., Manxeba, R., Hughes, C., Feley, P., Maroc, C., et al. (2011). Towards a youth employment strategy for South Africa. Development Planning Division Working Paper Series No. 28, Hlfway House: Development Bank of Southern Africa.

MerSETA. (2009). Analysis of workplace skills plans (WSP) and annual training reports (ATR) for merSETA member companies 2005-2007. Retrieved June 02, 2016, from http://www.merseta.org.za/innovation, researchanddevelopment.asp/

National Treasury. (2011). Confronting youth unemployment: Policy options for South Africa. Retrieved May 27, 2016, from http://www.africaneconomicoutlook.org/ fileadmin/uploads/aeo/PDF/Confronting $\% 2$ youth $\% 2$ unemployment $\% 20-\% 20$ Policy\%20options.pdf/

Neuman, W.L. (2012). Basics of social research: Qualitative and quantitative approaches. (3rd edn.). Hoboken, NJ: Pearson Education.

Nisbett, B.R.E. (2013). Schooling makes you smarter: What teachers need to know about IQ. American Educator 37(1), 10-19.

Nzimande, B. (2010). Report of the Further Education and Training Round Table of 9 April 2010. Retrieved June 02, 2016, from http://www.jet.org.za/events/fetcollege-round-table-and-summit/reports/

Nzimande, P., \& Patel, R. (2012). merSETA sector skills plan update 2012/13-2016/17: Promoting artisan development for employability. Retrieved June 02, 2016, from $\mathrm{http}: / / w w w . m e r s e t a . o r g . z a /$ innovation, researchanddevelopment.asp/

Pallant, J. (2013). SPSS survival manual. (5th edn.). New York: Open University Press.

Patel, R. (2012, December). Industry in college. Achieve: Leaders in Closing the Skills Gap, 18, 20-22. Retrieved May 27, 2016, from http://www.merseta.org.za/ merMEDIA/tabid/97/Itemld/279/Default.aspx/

Peo, D. (2013). Strengthening leadership in closing the skills gap: An overview of merSETA research-in-action. Retrieved June 02, 2016, from http://www.merseta. org.za/innovation, researchanddevelopment.asp/

Phillips, B.E. (2003). 'Hot' jobs in the auto industry! Where they are, how to get them. Hispanic Engineer and Information Technology, June/July, 16-17.

Piro, K. (2011). Investigating the impact of a psychometric assessment technique in the South African automotive industry. Unpublished doctoral dissertation, Nelson Mandela Metropolitan University, Nelson Mandela Metropole, Eastern Cape, South Africa.

Quinlan, C. (2011). Business research methods. Andover, Hampshire: South-Western Cengage Learning.

Ramdass, K. (2009). The challenges facing education in South Africa. In Higher Education Conference on the Impact of Mergers on the South African Higher Education System, 07-09 October 2009 (pp. 7-9). Pretoria, South Africa: Tshwane University of Technology.

Rauner, F., Heinemann, L., Hauschildt, U., \& Piening, D. (2012). Project report: COMET pilot test South Africa. Retrieved May 26, 2016, from http://www.merseta.org.za/ artisandevelopment.asp/

Rindermann, H., \& Thompson, J. (2011). Cognitive capitalism: The effect of cognitive ability on wealth, as mediated through scientific achievement and economic freedom. Psychological Science, 22, 754-763. https://doi.org/10.1177/09567 97611407207

Rohde, T.E., \& Thompson, L. (2007). Predicting academic achievement with cognitive ability. Intelligence, 35, 83-92. https://doi.org/10.1016/j.intell.2006.05.004

Schafmeister, A. (2013). Johnson Controls expands its interiors plant in East London, South Africa. Published company pamphlet. Burscheid, Germany: Johnson South Africa. Pub
Controls GmbH.

Schmidt, F.L., \& Hunter, J. (2004). General mental ability in the world of work: Occupational attainment and job performance. Journal of Personality and Social Psychology, 86(1), 162-173. https://doi.org/10.1037/0022-3514.86.1.162

Shahzada, G., Khan, U.A., Ghazi, S.R., \& Hayat, Y. (2015). Gender differences in selfestimated multiple intelligences among secondary school students. Pakistan Journal of Psychological Research, 30(1), 81-94.

Shatouri, R.M., Omar, R., \& Igusa, K. (2012). Towards a new era of sustainability in the automotive industry: Strategic human resource management and green technology innovation. World Academy of Science, Engineering and Technology, 69, 217-222.

Shea, D.L., Lubinski, D., \& Benbow, C.P. (2001). Importance of assessing spatial ability in intellectually talented young adolescents: A 20-year longitudinal study. Journa of Educational Psychology, 93(3), 604-614. https://doi.org/10.1037/0022 0663.93.3.604 
Smith, J.M. (2011). Connecting young South Africans to opportunity: Literature review and strategy. Cape Town: DG Murray Trust. Retrieved June 02, 2016, from http:// www.dgmt.co.za/files/2011/05/Literature-Review-Strategy.pdf

Spaull, N. (2013). South Africa's education crisis: The quality of education in South Africa 1994-2011. Report commissioned by Centre for Development \& Enterprise. Retrieved June 02, 2016, from http://www.section27.org.za/wp-content/ uploads/2013/10/Spaull-2013-CDE-report-South-Africas-Education-Crisis.pdf

Stieff, M., Dixon, B.L., Ryu, M., Kumi, B.C., \& Hegarty, M. (2013). Strategy training eliminates sex differences in spatial problem-solving in a STEM domain. Journal of Educational Psychology, 4, 607-615. https://doi.org/10.1037/a0034823

Stieff, M., \& Uttal, M. (2015). How much can spatial training improve STEM achievement? Educational Psychology Review, 27(4), 607-615. https://doi.org/ 10.1007/s10648-015-9304-8

Strand, S., Deary, I.J. \& Smith, P. (2006). Sex differences in cognitive abilities test scores: A UK national picture. British Journal of Educational Psychology, 76(3), 463-480. https://doi.org/10.1348/000709905X50906

Stromso, H.I., Bråten, I., \& Samuelstuen, M.S. (2003). Students' strategic use of multiple sources during expository text reading: A longitudinal think-cloud study. Journal of Cognition and Instruction, 21(2), 113-147. https://doi.org/10.1207/ S1532690XCI2102_01

Sun, S., Pan, W., \& Wang, L.L. (2010). A comprehensive review of effect size reporting and interpreting practices in academic journals in education and psychology. Journal of Educational Psychology102(4), 989-1004. https://doi.org/10.1037/a0019507

Taljaard, J.J. (1983). Manual for the Trade Aptitude Test Battery (TRAT). Pretoria: Human Sciences Research Council.

Ter Laak, J.J.F., Gokhale, M., \& Desai, D. (2013). Understanding psychological assessment. A primer on the global assessment of the client's behavior in educational and organisational setting. Delhi: Sage.

Tucker Drob, E.M., Cheung, A.C., \& Briley, D.A. (2014). National GDP, science interes and science achievement: A person-by-nation interaction. Psychological Science, 25(11), 2047-2057. https://doi.org/10.1177/0956797614548726
Uttal, D.H., Meadow, N.G., Tipton, E., Hand, L.L., Alden, A.R., Warren, C., \& Newcombe, N.S. (2013a). The malleability of spatial skills: A meta-analysis of training studies. Psychological Bulletin, 139, 352-402. https://doi.org/10.1037/ training st
a0028446

Uttal, D.H., Miller, D.I., \& Newcombe, N.S. (2013b). Exploring and enhancing spatial thinking: Links to achievement in science, technology, engineering and mathematics? Current Directions in Psychological Science, 22(5), 367-373. https://doi.org/10.1177/0963721413484756

Van der Berg, S., Taylor, S., Gustafsson, M., Spaull, N., \& Armstrong, P. (2011) Improving education quality in South Africa. Report for the National Planning Commission. Retrieved June 02, 2016, from http://esep.sun.ac.za/wp-content/ uploads/2012/10/2011-Report-for-NPC.pdf

Van der Merwe, A. (2008). A comparison of WISC-IV test performance for Afrikaans, English and Xhosa speaking South African Grade 7 learners. Rhodes University, Grahamstown.

Van de Werfhorst, H.G. (2014). Changing societies and four tasks of schooling: Challenges for strongly differentiated educational systems. International Review of Education, 60(1), 123-144. https://doi.org/10.1007/s11159-0149410-8

Van Hampton, T. (2007). Hidden cost of skills shortages. Engineering News-Record, 259(10), 34.

Vernon, P.E. (1964). The structure of human abilities. London: Methuen.

Vernon, P.E. (1965). Ability factors and environmental influences. American Psychologist, 20, 723-733. https://doi.org/10.1037/h0021472

Vernon, P.E. (1969). Intelligence and cultural environment. London: Methuen.

Wai, J., Lubinski, D., \& Benbow, C.P. (2009). Spatial ability for STEM domains: Aligning over fifty years of cumulative psychological knowledge solidifies its importance. Journal of Educational Psychology, 101, 817-835.

Watkins, M.W., Lei, P., \& Canivez, G.L. (2007). Psychometric intelligence and achievement: A cross-lagged panel analysis. Intelligence, 35, 59-68. 